\title{
The Effect of Serum Level of Albumin on Union of Tibial Closed Fractures: a Case Study of Iran
}

\section{Seyed Shahnam Moosavi', Mohsen Khorrami', Zeinab Khorshidi ${ }^{2 *}$}

'Department of Orthopaedics and Traumatology, Jundishapur University of Medical Sciences, Ahvaz, Iran

${ }^{2}$ Student Research Committee, Ahvaz Jundishapur University of Medical Sciences, Ahvaz, IR Iran

Study Area:Ahvaz, Iran

Coordinates: $231^{\circ} 19^{\prime} 13^{\prime \prime N} ; 48^{\circ} 40^{\prime}$ o9"E

Keywords: Prospective clinical trial,

The experimental procedures of this study was approved by the local ethics committee of Ahvaz Jundishapur University of mrdical sciences, Ahvaz, Iran (IR.AJUMS.REC.1395·328)

\section{Introduction:}

One of the main objective in any orthogeriatric department is identifying prognostic markers of evolution that allow early identification of the elderly patients with high risk of developing complications or identifying the patients who could benefit further intensive treatment to determine which patients may benef it from more intensive treatment (Pérez et al., 2010; Koren-Hakim et al., 2012; Saito et al., 2004).

Serum albumin levels are relatively inexpensive, reliable, and available to illustrate the nutritional status of orthopedic patients (Nakano et al., 2011; Symeonidis \& Clark, 2006; Pimlott et al., 2011). Serum albumin is a known proliferative agent in cell culture and has the ability to induce mesenchymal cell growth on the bone allograft surface (Yadav et al., 2015). Different studies have shown the effect of albumin on bone repair in both in-vivo and in-vitro conditions (Yadav et al., 2015; Ali, 2014; Yamaguchi et al., 2003). In elderly patients with a hip fracture, albumin levels below $38 \mathrm{~g} / \mathrm{L}$ are associated with a high risk of post-surgery complications, especially infections (Cabrerizo et al., 2015; O'Daly et al., 2010).

The level of serum albumin plays an important role in assessing the health status of the patients during hospital stay so that could be used as a strong predictor of early and late mortality after hospital discharge. Identifying these predictive factors could help in improving the case management during the hospital stay and more accurate discharge planning (Pioli et al., 2006).

\section{Abstract}

The impacts of albumin on fracture union process are not yet clearly understood. This study aimed to investigate the impacts of the serum level of albumin on closed tibial fracture union process by conducting a clinical trial on patients $(n=46)$ having closed tibial fractures. For all the patients, the albumin serum levels were recorded before surgery using blood tests. The patients were divided into two groups; the union group / the non-union of fracture and the group with union disorders. The albumin levels were compared between the two groups. The mean albumin level in the union group before the 6 months was significantly higher than the group with impaired union. Our findings contradict the previous findings necessitating conducting further studies with bigger sample size.

Disorder in the tibial fracture repair is a common challenge for surgeons. The exact role and mechanism of protein in improving the tibial fracture repair is not yet understood. Therefore, the present study aims to investigate the effects of serum levels of albumin on union of fractures.

\section{Materials and methods:}

This study was designed as a prospective trial on 69 patients with tibial fractures candidate of surgical nail fixation referred to Imam Khomeini and Golestan Hospitals, Ahvaz, Iran. The serum levels of albumin of all patients were measured and recorded before surgery. Serum albumins $=3.5$ and $<3.5$ were respectively considered as the normal and abnormal. After the hospital discharge, the formation of fracture union was evaluated by clinicalradiographic evaluation (anterior and lateral examination) weekly up to 4 weeks after surgery and then monthly. The union was measured with radiographic union score for tibial (RUST) score, where RUST score of $7 \%$ is acceptable. The RUST score, some scores were assigned to all four cortices (the fracture line without the formation of callus= 1 ; callus and the fracture line $=\mathbf{2}$; callus without a fracture line $=3$ ) and their sum was considered the final score. The union times were recorded for each patient. Informed consent was received from all patients.

Inclusion criteria were the patients with closed tibial fracture, nail fixation surgery. The exclusion criteria were an open fracture, history of fractures in the limbs, smoking, alcohol addiction, long-term use of anabolic steroid drugs, 
osteoporosis, metabolic disorders, and diabetes. During the study, 23 patients were excluded from the study for various reasons including mortality, migration and inaccessibility, rebound fracture, lack of referral after opening splint, and the impairment diagnosis in laboratory response. Finally, the results of 46 patients were collected and data were analyzed with statistical package SPSS (Windows, version 22) using T-test, Chi-square $\left(\mathrm{X}_{2}\right)$, Pearson correlation, and regression tests.

\section{Results:}

Forty-six patients belongs to mean age of $29 \pm 9.1$ years participated in the study and were divided into two groups according to the duration of treatment: union who formed a union in 6 months $(n=29)$ and nonunion who did not form a union within 6 months $(n=17)$. There were no significant differences between the two groups on the distribution of genderand age (Table-1).

Table-1:- Demographic information of patients

\begin{tabular}{lllll}
\hline Variables & & Union & Nonunion & P-Value \\
\hline Gender & Men & $26(89.7 \%)$ & $14(82.4 \%)$ & $>0.478$ \\
& Women & $3(10.3 \%)$ & $3(17.6 \%)$ & \\
Age (year) & $27.7 \pm 7.8$ & $31.3 \pm 10.7$ & $>0.199 \backslash$ \\
\hline
\end{tabular}

The mean albumin level of patients with a union before 6 months was signif icantly higher than that of the nonunion patients (Table-2).

Table-1:- Demographic information of patients

\begin{tabular}{rllll}
\hline Variables & & Union & Nonunion & P-Value \\
\hline Albumin & $<3.5$ & $1(3.4 \%)$ & $4(23.5 \%)$ & $>0.035^{*}$ \\
& $\geq 3.5$ & $28(96.6 \%)$ & $13(76.5 \%)$ & \\
\hline
\end{tabular}

*The difference is significant at the 0.05 level

The albumin level in patients whose bone union formed less than 6 months was assessed separately against the union time per month. There was no significant difference in the albumin levels between the groups (Table-3).

Table-1:- Demographic information of patients

\begin{tabular}{lllllll}
\hline Variables & \multicolumn{5}{c}{ Time of Union (month) } & P-Value \\
& & 3 & 4 & 5 & 6 & \\
\hline Albumin & $<3.5$ & o (o\%) & o (o\%) & $1(100 \%)$ & o (o\%) & $>0.512$ \\
& $=3.5$ & $7(25 \%)$ & $12(43 \%)$ & $8(28 \%)$ & $1(4 \%)$ & \\
\hline
\end{tabular}

The relationship between albumin level and the time of fracture union was calculated using Pearson correlation coefficient (Table 4).

Table 4: Correlation relationship between albumin \& union time

\begin{tabular}{lll}
\hline Variables & Mean \pm SD & Correlation \\
\hline Albumin & $4.2 \pm 0.49-$ & $>0.177$ \\
Time of Union & $4.14 \pm 0.83$ & \\
\hline
\end{tabular}

The Pearson correlation coefficient test demonstrated an inverse relationship between the albumin level with a time of union formation in which increasing the albumin level decreases the union time but the relationship was not statistically signif icant ( $\mathrm{p}>0.05$ ).

In addition, regression analysis was used to assess whether or not the variations in the albumin level possess predicting a value for the time of the union of fewer than 6 months (Table-5).

Table 5: Predicting union time based on albumin in patients with union less than 6 months

\begin{tabular}{|c|c|c|c|c|c|}
\hline $\begin{array}{l}\text { Criterion } \\
\text { variable } \\
\end{array}$ & $\begin{array}{l}\text { predictor } \\
\text { variable }\end{array}$ & $\mathrm{R}$ & $\mathrm{R}_{2}$ & $\begin{array}{l}\text { ANOVA } \\
\text { F Value } \\
\end{array}$ & $\mathrm{p}$ Value \\
\hline $\begin{array}{l}\text { Time of } \\
\text { Union }\end{array}$ & $\begin{array}{l}\text { Constant } \\
\text { Albumin }\end{array}$ & 0.193 & 0.041 & 0.388 & $>0.520$ \\
\hline \multicolumn{6}{|c|}{ Coeff icients } \\
\hline & B & SE & \multirow[t]{2}{*}{ B } & $\mathrm{T}$ & p Value \\
\hline & $5 \cdot 55$ & 1.9 & & 2.86 & $<0.009$ \\
\hline & -0.284 & 0.43 & -0.149 & 0.661 & 0.516 \\
\hline
\end{tabular}

Table -5 shows that the albumin level explains $4.1 \%$ of the total union variance in patients with less than 6 months of the union $(\mathrm{R} 2=0.041)$. One-way analysis of variance (ANOVA) did not report prediction of union time by albumin as significant $(\mathrm{F}=$ 0.388 and $\mathrm{p}>0.520$ ). Considering the reported prediction coefficients of union time prediction, albumin is not an effective variable to predict union time in patients.

\section{Discussion:}

The study investigated the effect of albumin serum levels on the union of tibial fractures. We found a positive correlation between albumin serum levels of and the time of the union of tibia fractures which would urge physicians to pay more attention to the serum levels of albumin in these patients. Moreover, this must be included in laboratory routine tests and targeted as a therapeutic marker and given nutritional recommendation and supplements shorten the time of union. The results showed that albumin levels in patients with the union less than 6 months were significantly higher than patients with union disorder. The results of Sabir et al. (2016) showed that serum albumin has a positive correlation with the progression of fracture repair of tibia shaft. In a cohort study, Sabir et al. (2014) examined the relationship between serum albumin and progression in bone repair. The results showed a positive correlation between serum albumin and improvement in the repair of a fracture of the tibial shaft. They proposed their serum albumin as a primary marker for the union probe of the tibial shaft fracture. The results of both studies were in line with our study.

In the present study, we found no significant differences between the level of albumin and union time in patients with union for less than 6 months. There was an indirect relationship between the mean levels of albumin with mean union time in the patients with union less than 6 months so that the increase in albumin levels decreased union duration, but this relationship was not statistically 
significant. In the present study, albumin failed to predict union time in patients significantly. The results of Koval et al. (1999) reported a significant correlation between serum albumin levels of less than 3.5 and union delay, hospitalization time, and increased mortality. The results of two studies by Pimlott et al. (2011) and Steinberg et al. (2014) showed a significant relationship between serum albumin levels and mortality and postoperative complications in patients with femoral fractures and serum albumin levels were as a prognostic factor in these patients.

Given the results of the studies conducted, one can use serum albumin levels as a prognostic factor for union and prevention of impairment of tibia fractures repair. In addition, given the reverse relationship between serum albumin and union time, and no signif icant relationship in this study, more studies are recommended to examine the effect of serum albumin and union time.

\section{Acknowledgment:}

We are thankful to particinats and the other medical staffs who have helped us to conclude this study.

\section{References:}

Ali, S., Singh, A., Agarwal, A., Parihar, A., Mahdi, A.A. \& Srivastava, R.N. (2014): Does the nutritional status changes the healing outcome of simple diaphysel tibial fractures in adults: A prospective cohort study. Int. J. Biomed. Adv. Res., 5(4)207210.

Ali, S., Singh, A., Mahdi, A.A., Srivastava, R.N. \& Shantanu, K. (2016): Does serum albumin level affect the healing outcomes of simple diaphyseal tibial fractures? Saudi J. Med. Med. Sci., 4(2):93-97.

Cabrerizo, S., Cuadras, D., Gomez-Busto, F., Artaza-Artabe, I., Marín-Ciancas, F. \& Malafarina, V. (2015): Serum albumin and health in older people: review and meta-analysis. Maturitas, $81(1): 17-27$.

Koren-Hakim, T., Weiss, A., Hershkovitz, A., Otzrateni, I., Grosman, B., Frishman, S., Salai, M. \& Beloosesky, Y. (2012): The relationship between nutritional status of hip fracture operated elderly patients and their functioning, comorbidity and outcome. Clin. Nutr., 31(6):917-921.
Koval, K.J., Maurer, S.G., Su, E.T., Aharonoff, G.B. \& Zuckerman, J.D. (1999): The effects of nutritional status on outcome after hip fracture. J. Orthop. Trauma, 13(3):164-169.

Nakano, T., Kuwabara, A. \& Tanaka, K. (2011): Overestimated serum albumin levels in patients with hip fracture. Clin. Nutr., 30(2):261.

O'Daly, B.J., Walsh, J.C., Quinlan, J.F., Falk, G.A., Stapleton, R., Quinlan, W.R. \& O'Rourke, S.K. (2010): Serum albumin and total lymphocyte count as predictors of outcome in hip fractures. Clin. Nutr., 29(1):89-93.

Pérez, D.F.D., Ruiz, L.M.D., Bouzas, P.R. \& Martin-Lagos, A. (2010): Nutritional status in elderly patients with a hip fracture. Nutr. Hosp., 25(4):676-681.

Pimlott, B.J., Jones, C.A., Beaupre, L.A., Johnston, D. \& Majumdar, S.R. (2011): Prognostic impact of pre-operative albumin on short-term mortality and complications in patients with hip fracture. Arch. Gerontol. Geriat., 53(1):90-94.

Pioli, G., Barone, A., Giusti, A., Oliveri, M., Pizzonia, M., Razzano, M. \& Palummeri, E. (2006): Predictors of mortality after hip fracture: results from 1-year follow-up. Aging Clin. Exp. Res., 18(5):381-387.

Saito, N., Tabata, N., Saito, S., Andou, Y., Onaga, Y., Iwamitsu, A., Sakamoto, M., Hori, T., Sayama, H. \& Kawakita T. (2004): Bone mineral density, serum albumin and serum magnesium. L.Am. Coll. Nutr., 1;23 (6):701S-703S.

Steinberg, E.L., Amar, E., Sagy, Y., Rath, E., Kadar, A. \& Sternheim, A. (2014): The impact of serum albumin and serum protein levels on POSSUM score of patients with proximal femur fractures. Injury, 45(12):1928-1931.

Symeonidis, P.D. \& Clark, D. (2006): Assessment of malnutrition in hip fracture patients: effects on surgical delay, hospital stay and mortality. Acta Orthop. Belg., 72(4):420-427.

Yadav, M., Singh, A., Ali, S., Rizivi, N., Hussain, S. \& Kumar, V. (2015): Role of Serum Albumin in fracture healing. Int. J. Biomed. Res., 6(7):452-455.

Yamaguchi, M., Igarashi, A., Misawa, H. \& Tsurusaki, Y. (2003): Enhancement of albumin expression in bone tissues with healing rat fractures. L. Cell. Biochem., 89(2):356-263. 